move the directions comfortably. Unlaminated directions inevitably get ripped, blackened or written on, and unanchored instructions may disappear. Instructions in notebooks are simply not as obvious.
Perhaps I haven't moved the earth with any of these revelations. However, even in a complex information age, simple ideas can continue to be expressed ... . and found to work.

\title{
Employing library student assistants as student supervisors
}

\author{
By F. Jay Fuller
}

\author{
Assistant Building Manager \\ California State University Library, Chico
}

As college and research libraries enter the decade of the nineties, we are confronted with numerous challenges. How do we manage the newest information technologies, which are becoming increasingly global in reach and ever more intricate in nature? How do we answer the complex questions concerning copyright and privacy laws, which are no longer raised as issues of black and white, but as controversies in charcoal and gray? And how are we going to increase, or even maintain, the required levels of library service our academic communities demand, when we find that our operating budgets no longer stretch as far as they once did to meet such demands?

How we will deal with our new technologies will depend on the impacts that occur as we use them, and certainly the large, theoretical issues, such as the public's right to know versus the individual's right to privacy, will take much debate, if not litigation. These questions will all take time; however, for many of us, our problems concerning essential library service are urgent, and time will only increase our difficulties if we don't make the necessary adjustments.

At the Meriam Library on the campus of California State University, Chico, we have attempted, quite successfully, to meet this question of service through our unique Student Supervisor program, and we have found that instituting it was one of the best decisions we have ever made.

Starting in 1970, we shifted responsibility for the evening and night supervision of student assistants in our stacking operations from a regular staff employee to two experienced student assistants. These student assistants were given the title "student supervisor," and were given a slightly higher wage than that of their peers. Initially the duties performed by these individuals were limited in scope, and amounted to very little more than occasionally checking to make sure that the other student workers on their shifts were present, and that they were completing the tasks assigned to them in a reasonable and timely manner.

The manager of student personnel monitored and scrutinized the progress of the program at this initial stage for an entire year. The results were quite positive. After two semesters, it was decided to expand the program to five individuals and to have them work all shifts, day and night, to give them more training in basic personnel management, and to give them slightly more latitude in supervising and training the student assistants in the stacking unit. After the second year, it was found that the level of service in the stacking unit had improved significantly, as had overall efficiency and morale, without increasing funding or the total number of individuals employed. The following year, the third in the program's history, the program was further expanded to include some of the other service units, and today student supervisors are to be found in nearly every department in the Meriam Library, public and technical.

The successful results of this program have been twofold. With the complexities inherent in some of our unit's operations with regard to procedures and computerized records, it would be extremely difficult to train rookie student assistants in every detail of that unit's daily routines, in a reasonable period of time, and expect them to function as supervisors of other student workers within that department as well. Therefore, all the individuals chosen for this program have been experienced library workers On average, student assistants selected have been in their respective departments for at least two semesters, have proven to be proficient in their unit's operations, and have received outstanding 
evaluations before promotion to the student supervisor rank.

In conjunction, the staff in the various departments, except for those with few student employees, have been willing to relinquish the daily task of direct supervision of all the student workers in their units. This has not always been easy. Staff, with understandable justification, believe that whatever happens in their departments, good or bad, is their responsibility. However, they have graciously accepted their roles as mentors and guides for the student supervisors in their areas, and have found that putting their trust in these student workers to handle the job of daily student assistant supervision to be well placed.

From the staff perspective, this program has improved service on a number of levels. First, although the library staff in the public and technical areas still select all the student workers for their departments from interviewees sent to them by the manager of student personnel, they are no longer burdened with the task of training each new student assistant in the department's fundamental operations. Student supervisors do the basic training of all the new student workers, leaving the regular staff free to concentrate on the vital work of their departments, especially during some of the more trying times of the year (for example, the beginning of semesters), without being constantly interrupted to reiterate basic instructions, policies or procedures to inexperienced employees.

Second, many of the normal questions or problems which occur during the day can be easily handled by the student supervisors themselves without involving a regular staff member. These individuals are well versed in the department's policies and procedures, and are more than capable of dealing with routine types of questions or difficulties which may arise. If patrons aren't satisfied with the answer given by a student supervisor, they are certainly welcome to request to speak with a higher authority. But, if even fifty percent of the time the patron accepts the answer or solution given by the student supervisor (we find the actual percentage to be closer to ninety-five percent), regular staff members of the department have that much more time to dedicate to the larger, more complex, and demanding problems that arise during the course of the day.

And, third, the student supervisor serves as a model for the professional conduct and personal decorum expected of all the department's student assistants. It is one thing to have these expectations presented in written form via a departmental manual, but they take on a more meaningful and defined character when the senior student personnel of the department are observed living up to these expectations during the course of their work. The end result is that all student assistants in the department are encouraged to strive for the level of service rendered by their peers, the student supervisors, without requiring substantial staff reinforcement of dress codes, common courtesy towards patrons, punctuality, etc.

The many ways this program has improved library service from the perspective of the student assistants is somewhat more subtle, but just as important. A student supervisor position is coveted by nearly every student employee. It brings with it a higher wage, some prestige, and tangible evidence that the regular staff have found that student employee's work performance to be superior in quality. The position provides for and allows the individual more freedom of action and greater responsibility, and gives the student worker a chance to learn and cultivate administrative and leadership skills. These aspects of the student supervisor program serve as incentives for all student employees to do well on the job, because it is their job performance that will be the primary factor in determining who will be promoted, and who will not.

Additionally, the program has provided student assistants a substantial reason for staying with the library as employees. The longer they work in one of the library's departments, the greater their chances become that they will be promoted to a student supervisor position. This single factor has nearly eradicated, at our library, a major problem concerning student assistant employment for other libraries, the problem of a high student employee turnover rate. Students stay with our library because they perceive the student supervisor program as a real indication that we care about our student workforce, and respect their abilities and talents as contributors to the operation of the library as a whole.

Also, the individuals who are chosen for this program have demonstrated that they take great pride in the service they render. There is almost a spirit of proprietorship generated in these student employees, and it manifests itself in their attitude, morale, and work ethic. For them, the library is not just a place of employment; it is their library. They are responsible, in some measure, for the way it functions on a daily basis, and have a limited voice in how it will function in the future.

In this vein, we believe that it is important to listen closely to our student supervisors when they suggest changes in service policies and/or procedures. It is to our great advantage that these mature individuals are not simply employees working at our public service counters and in our technical service areas, but that they are also students who use the library every day as patrons. They know the present system from the inside, and they can provide us with valuable insights as to what will be needed tomorrow or next year to insure that the 
information they require, as students seeking academic degrees, can be placed in their hands effectively and efficiently.

There is one final aspect of our student supervisor program that has been of immeasurable benefit to our library in terms of service. The tasks performed by the student supervisors are so varied that these individuals are capable of moving easily from their positions as student workers to become regular staff employees within their departments. Approximately thirty percent of the regular, full-time staff currently employed by the Meriam Library started their library careers as student assistants and were involved in our student supervisor program. These individuals have, in many cases, been able to step from their student work into a staff job and almost immediately function at full capacity. Thus, the need for an extended training period has been eliminated for these employees, because they are knowledgeable about the department's policies and procedures on their very first day. This has permitted the periodic transitions in regular staffing, which occur because of transfers or retirement, to be smooth and relatively immune to temporary service slow-downs that typically occur as a new employee becomes familiar with the basics of a unit's operation.

In all, we have found that our student supervisor program has helped our library to provide a level of public and technical service that otherwise would probably have been unattainable. In addition, we have tapped a valuable, internal library resource for guidance towards improvements in our future service, and have given a number of bright, energetic, and enthusiastic young adults a chance to lay foundations for the leadership skills they will need throughout their careers. We believe it to be a good program that has served well all those involved with it, staff and students, and one that we look forward to continuing and expanding upon well into the next century.

\title{
Humor and creativity: Questions and answers
}

\author{
By Norman D. Stevens
}

Director

The Molesworth Institute

As librarians, answering questions-correctly or incorrectly-is our stock-in-trade; it is not surprising, therefore, to find that various aspects of the question and answer game lend themselves to creative approaches that generate humor. In some cases it is the questions that users ask at the information or reference desk that generate, usually unintentionally, the humor. In other cases special humor issues of library newsletters that contain mock advice to the library lorn are a special delight. In still other cases academic libraries have created imaginative forums in which to answer written comments, complaints, questions, or suggestions. Each brings its own unique view of the world of library humor.

\section{At the reference desk}

Nancy S. Osborne, of the SUNY College at Oswego Library, observes that, "students asking pre-exam questions fall in a number of categories: the desperate, the confident, the confused, the organized. The questions fall into categories too: thoughtful, cognitive; hasty, rapid; penetrating and searching; inane and perhaps irrelevant. ... [In responding] I maintain that the existence and willing utilization of an active, healthy, and operative sense of humor, can make all the difference."

Perhaps that is what Lynne S. Epstein, then of the University of Kansas Medical Center Library, had in mind when she answered the phone one day-in the midst of a discussion with her supervisor about eating-by saying, "Reference. This is Lynne. May I feed you?" The patron responded, "You certainly may. What are you serving?" Lynne's supervisor provided the final note of indignity by point out that, given Lynne's history of cooking failures, she might better have said, "Reference. Will you feed me?"

Equally baffling must have been the greeting given by an assistant at the Winnipeg Public Library, where Randy Reichardt worked, who answered the phone one day not with the usual, "Good afternoon. Information and Reference," but with the unusual, and perhaps more accurate, "Good afternoon. Reformation and Inference."

A startling miscue, although not in the context of a true information exchange with a patron, was generated by a colleague (to remain nameless) who, when leaving for the reference stacks with a 